of all electric conductors, attention was turned to the open or uncovered wires. The line running from Berlin to Magdeburg, a distance of 93 miles, was selected. The comparison was made between a wire $2 \mathrm{~mm}$. (.078 inch) in diameter and 93 miles long, and another of $3 \mathrm{~mm}$. (.118 inch) in diameter and $111 \% / 4$ miles long. Fig 2 shows the manner of equipping the former wire with the coils, as well as the double insulator. The coils were placed upon poles $2 \frac{1}{2}$ miles were place upon poles $21 / 2$ miles apart, and it was found that the as-
sisted smaller wire far surpasse the work performed by the larger wire. In Fig. 3 we show a pole with a number of coils attached. These results prove that in the Pupin inventions, new means are provide for greatly increasing the speaking property of cables. The day may not be so very far in the future before New York and London, Paris, Berlin, Vienna, or St. London, Paris, Berlin, Vienna, or St.
Petersburg may be telephonically connected, and "Hello London," will be a common expression in Wall Street. The coils necessary to assist a wire are not too large to be placed in the sheathing of a transatlantic cable. Hence such a cable is by no means an impossibility. Such coils, if placed at proper inity. Such cols, if placed at proper in tervals, may not exceed an inch in length with a diameter of half an inch. With the Marconi wireless telegraphic and the Pupin relay telephonic sys-
tems in working order, the era of quick and easy communication will have arrived

\section{A STEEL CABOOSE AND REPAIR CAR.}

$$
\text { BY GEORGE J. JONES }
$$

With steel cars now coming largely into use, en tirely new problems of maintenance and repair are encountered. When a wooden car is wrecked in a collision or other accident, the problem generally pre sented is that of getting the debris out of the way as soon as possible and to subject the following trains to the least possible delay. But in the case of the stee car the domage sustained is of an entirely different character. With the proper facilities at hand, it is necessary only to replace a tew parts, to straighten out a few others, and the car is ready to proceed to its out a few o
destination.

The Goodwin Car Company has been the first to meet these change conditions by the construction o a combined raboose and repair car, which is designe to accompany trains of the dumping cars built by that company. Such a car is shown in the accompanying cut, and was built for the Carnegie Steel Company a part of a train which that concern is now operating in the vicinity of Pittsburg. One of the features of in the vicinity of eittsburg. One of the features of superiority of this car over the caboose of wood is its
great strength. It has but two sills, which are of steel and form the backbone of the car, being situated whatever could be found with its behavior. As a repair shop, this car is fitted with the pneumatic tools which are necessary to remedy any ordinary damage that will be encountered on the road, and which are operate from the train-line pressure of the air-brake system. The car parts are all interchangeable, and the repair car is titted out with duplicate cate as been drawn to what has been Canal, considerable attention has been drawn to what has been Teltow Canal, nearly forty miles in length, it is said, would carry nearly five million tons per annum, connecting as it does the rivers Spree and Havel. The committee in charge of the competition offered prizes of about $\$ 3,000$ for the best electric system of canal haulage. A score of applicants took part in the compeof app
tition.

It may be of interest to consider some of the work in electric canal haulage before going into the details of these tests. In Germany, France, America, and other countries experiments have been made with electric canal haulage systems with varying success during the past ten years or more. Recently it has been seriously questioned whether the railroads would be able to supersede the canals entirely or even compete successfully against them, when electrically equipped, for moderate speed transportation of freight. The general tendency is to enlarge canals to accom. modate larger boats. The Erie Canal has been somewhat enlarge and will undoubtedly soon be reconstructed,
and equipped for handling immense quantities of
reight. The Oder-Spree Canal was enlarged for boats

\section{A STEEL CABOOSE AND REPAIR CAR.}

parts. Where it is necessary, it will be a comparatively easy matter to cut out a broken part and substitute a new one. A special tool is provided on the car for doing this work quickly. By means of this tool the rivets are cut out so that new parts can be substituted. With the usual cold chisel and sledge hammer, it would be impossibie to accomplish much in difficult

The tool in question consists of an ordinary piece of hydraulic piping with a series of cutting teeth on one end, the other end being fitte to the drill ordinarily use with the pneumatic equipment. These teeth being allowe to operate on the head on the rivet, cut it away until it can be driven out with little difficulty. In the construction of the steel cars, bolts are used instead of rivets on all parts which are most liable to damage while on the road by reason of accident. These parts can then be removed and replaced merely by the use of a monkey wrench, which feature further simplifies the matter of repairs on the road.

The steel caboose also can be used as an observation car, being supplied with a cupola and a railing around the top of the car. From this point the operation of the entire train can be observed. By opening an air-valve at one end of the car, any car or the train alve at one end of the car, any car or the whole train can be dumped either at the side of the track
or in the center. This feature is of great advantage places under the car. of 450 tons. The Dortmund-Ems Canal boats have a capacity of 750 tons. Large boats are also to be found on the great Mittelland Canal.

Lamb's aerial system was teste in America on the Erie Canal near Buffalo some years ago and on the Finow Canal near Eberswald, Germany. A strong steel cable is use in this system for supporting the motor carriage. The current is received from an overhead trolley wire and travels along the suspended cable. The steel cables are all supported on posts along the bank of the canal. The propelling mechanism consists of a revolving drum which winds itself on and along a second steel cable provided for the purpose. The
length of the system installed for this test was somewhat less than half a mile.

The motor used was of about 1 ton weight, 500 volts pressure, and of 5 horse power capacity, while the speed attaine was about 13,000 feet per hour, or 3.6 feet per second. On canals of many curves and turns the suspended system of haulage is open to tine objection that many supporting posts are required. The weight of the heavy cable is said to be an objection; besides, many engineers contend that the cost besides, many engineers contend that the cost of mainfenance would be high. for this system is that it leaves the bank free.

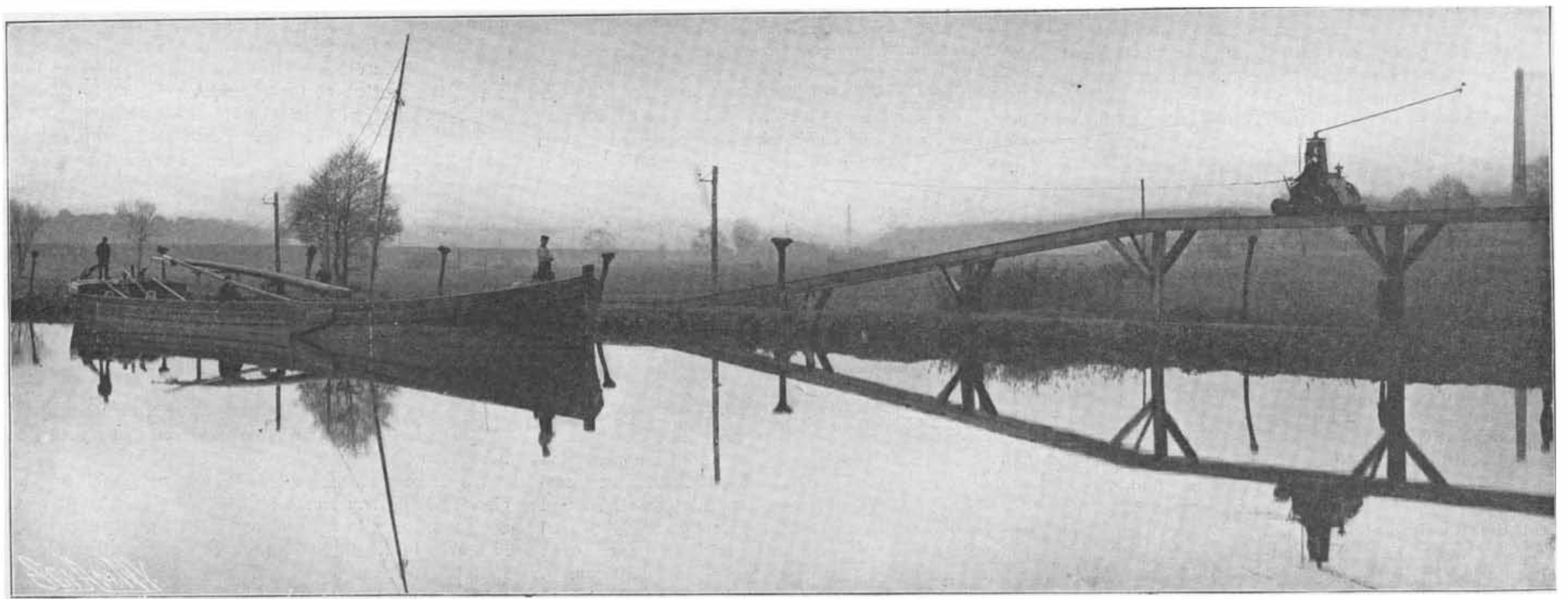

TOWING CANALBOATS BY ELECTRIC LOCOMOTIVES (ROETTGEN SYSTEM).

on the line of the draft and pulling strains. The rigidity thus obtained is especially desirable where it is found necessary to make use of pushing engines on mountain grades. One of the most common forms of accident is the result of the collapse of the caboose in these trying circumstances. The sudden application of the brakes at the head of the train on a slight grade has been known more than once to smash the caboose into splinters, killing or maiming the occucaboose into splinters, killing or maiming the occu-
pants. The steel caboose has already been put to test of this character in actual practice, and no faul in trestle filling and storage
portation and for filling work.

The dahlia is a plant prized solely for its bloom, yet were all the Irish potatoes to be destroyed, it is possible that this plant would to some extent replace them. Roasted, the dahlia bulb is wholesome and toothsome and makes a not bad substitute for the potato. When first introduce into Europe, it was not for its flower, but as a vegetable that it was valued. -G. E. M.
The Koettgen electric canal haulage system employs one rail in some cases and two rails in others wher tests have been made as on the Finow Canal. The electrical equipment was supplied by Siemens \& Halske of Berlin. The length of track used was about 3,300 feet and an electric locomotive is employed for hauling the canalboats. The single rail is place far. thest from the canal so as to impede other traffic on the canal as little as possible. Two of the locomotive wheels are grooved, are small in diameter, and carry
more than three fourths of the weight. These small 